García-Peñalvo, F. J., Conde-González, M., \& Matellán-Olivera, V. (2014). Mobile Apps for Older Users - The Development of a Mobile Apps Repository for Older People. In P. Zaphiris \& A. Ioannou (Eds.), Learning and Collaboration Technologies Technology-Rich Environments for Learning and Collaboration. First International Conference, LCT 2014 Held as Part of HCl International 2014 Heraklion, Crete, Greece, June 22-27, 2014. Proceedings, Part II (Creta Maris, Heraklion, Crete, Greece, June 22 - 27, 2014) (pp. 117-126). Switzerland: Springer International Publishing.

\title{
Mobile apps for older users. The development of a mobile apps repository for older people
}

\author{
Francisco J. García-Peñalvo ${ }^{1}$, Miguel Á. Conde ${ }^{2}$, Vicente Matellán-Olivera ${ }^{2}$ \\ Computer Science Department. Science Education Research Institute (IUCE) \\ GRIAL Research Group \\ University of Salamanca, Salamanca, Spain \\ fgarcia@usal.es
}

Department of Mechanical, Computer Science and Aerospace Engineering. Robotics Research Group. University of León, León, Spain.

\{miguel.conde, vicente.matellan\}@unileon.es

\begin{abstract}
The emergence and application of the information and communication technologies have changed the tools that people use in their daily life. However not all the collectives use the technology in the same way. One case to take especially into account is older people. For them technology should be an inclusive factor but it can be also exchusive. The use of mobile devices and mobile apps by older people is an example of this. The devices and the apps are not always adapted for the special abilities or features of older people; moreover they do not always meet their needs. In order to facilitate older people access to mobile apps the present work reviews the usability issues to take into account and poses a repository of apps adapted and classified taking into account usability issues related to older people.
\end{abstract}

Keywords. Older people, ICT, mobile apps, usability, needs

\section{Introduction}

Since the late 1990s access to information and communication technologies (ICTs) has seen tremendous growth - driven primarily by the wireless technologies and liberalization of telecommunications markets. The impacts of ICTs cross all sectors. Research has shown that investment in information and communication technologies is associated with such economic benefits as higher productivity, lower costs, new economic opportunities, job creation, innovation, and increased trade. ICT application also helps to provide better services in health and education, and strengthen social cohesion [1]. ICT has become something natural in people daily life. However all persons do not use it in the same way. 
An example of this is older people. Older people are also known as elderly people or senior citizens, however during this work the expression used to name them is "older people" as several experts recommend [2]. What is understood as older people? It depends on the context, in Europe an older person is not the same as in Africa, most developed countries set the age of 65 years to define when a person is older. At the moment, there is no United Nations (UN) standard numerical criterion, but the UN agreed cut-off is $60+$ years to refer to the older population [3]. In this paper this last age is used to consider who is an older person.

These older people have special features and use ICT in a different way from the people that have grown surrounded by ICT. This fact implies a digital gap between the former group, named digital immigrants, and the latter, known as digital natives $[4,5]$.

Moreover, ICT has high potentiality for inclusion and exclusion for older people. It can help to include older people because ICT and specially, older-adapted ICT, can reduce de digital gap [6], increase social interaction and improve older people quality of life. ICT helps them to access to learning activities, gives them health information, provides a new way to interact with family and friends, etc. [7, 8]. However the use of these technologies is not easy for older people, the devices and technologies are not always adapted to their real needs and they find such technologies and tools expensive [9-11]. Surveys such as "ICT and Older people. Connected to the future" from Vodafone Spain Foundation, show that people between 56 and 70 years are in favour to use new technologies, which implies that exclusion is being reduced. [12].

Mobile technology can be seen as an example. Mobiles are one of the technologies with a greater penetration and acceptation in our society. In 2013 there are more than 6800 millions of subscriptions in the world and more than a mobile device per person in the developed countries [13]. These devices provide access to a complete set of services that can be employed with different purposes. A high percentage of older people in developed countries owned one of these devices, however they use only mobile phones for very limited purposes, such as for calling or texting in emergencies. This is mainly caused because the devices are not adapted to their needs, because they need to learn to use the device and they have been not thought thinking in their special features [12, 14]. Adaption of mobile services and apps is not new [15-17], however in this case a very specific collective is considered.

Given this context, there is a need to facilitate older people mobile apps adapted to them and that facilitate their access to other of the services provided by such kind of devices. To deal with these problems several issues should be taken into account:

- It is necessary to study the usability in this kind of devices and specifically if the devices and apps are adapted older people.

- It is necessary to study what are the apps and tools that this collective want and needs. That is, take into account older people real necessities and not only what the apps developers think they have.

- It is necessary to explore existing repositories of mobile apps for older people.

In order to order to do this the present work studies: the different existing studies about usability in mobile devices for older people, those that consider how the mobile apps included in the devices are adapted for them and which of those apps they are 
really using. With this information an application for classification, storage and recommendation of mobile apps is defined. It acts as a repository for mobile apps and it is tested with a set of mobile apps and enriched with older people feedback about them.

The paper is structured as follows: the following section (Section 2) presents the related works, including usability studies, necessity surveys and other repositories of tools for older people; after it the approach to carry out the repository is presented and also the evaluation methodology (Section 3); finally (Section 4) some conclusions are posed.

\section{Related Works}

The idea of the definition of repository of apps is not new, but in this case the apps stored into it are oriented to a stakeholder with very specific abilities and necessities, the older people.

These people use the mobile phones and apps in a different way from other collectives, they interact with mobiles in other ways, they have other worries, need other functionalities, etc. [18]. As the ongoing work consists of the definition of a repository of apps for older people it is necessary to explore the usability of this devices and apps for them and also what they need from this technology.

\subsection{Mobile phones usability for older people}

The usability measurement of any kind of device or application is not an easy task. It implies to consider several dimensions that can be different depending on the authors, some of most common are the execution time, performance, final user satisfaction and ease to learn [19]. In addition, this dimensions cannot always been applied in the context of mobile technologies given the special features of this devices and that they are continuously evolving [20]. In this sense there are several studies that consider mobile usability such as [20-25]. However they are very focused in the device and no so much in a different final user of the device as a senior citizen is.

Regarding the works that study the usability for older people, Villaseca [26] made a review of different studies in this sense. This study shows that older people require more time to complete tasks on mobile devices [27] and it describes problems such as: the size of the screen to read information, the size of menus and interfaces to enter data such as keyboards (virtual and physical), functionalities such as de drag and drop, the size of the target (the older tend to make errors when tapping a small target), the gap between intended and actual touch locations (the older tend to miss their intended targets due to parallax and the large contact area of each finger) [28-32]. In addition Villaseca [26] also carry out an experience from which they extract that for older people there are also other issues very important related to mobile devices such as: characters in the screen easy to read, buttons easy to use, that the device was easy to learn and operate, keep in contact, good sound quality, etc. 
If these and other factors were taken into account to define more usable interfaces it would be possible to compensate performance decrements as present in older adults [18].

These studies present two problems: 1) mobile technologies and mobile interfaces are evolving very quickly, this means that the usability issues considered by them can be old-fashioned in a short period of time; 2) the existing studies are specially focused usability issues of the devices but also apps and mobile operating systems should be taken into account.

\subsection{Mobile phones usability for older people}

The study of usability in mobile devices apps is not something new; there are several works that explore this issue [33-35]. However in this case the important issue is how to define usable apps for older people.

Usability in apps for older people used to be linked to the requirements they have from this devices [36] (that is discussed in next subsection). For instance some of the features to include in mobile apps and in mobile devices designed for older people are [14]: Memory aids (e.g.: appointments, reminders, address book with photos, personal Information, standardised menus, personalized menus), Visual aids (e.g.: backlight, large text, bold colour, colour scheme and big buttons, etc.), Haptic aids (e.g.: a rubber grip and easy-to hold phones), Features to minimise user error (e.g.: keypad autolock, extra confirmation dialog and noticeable reminders); And safety features (e.g.: panic button and speed-dial).

Authors such as Lorenz and Oppermann [37] describe some requirements for mobile applications: The font size should be between $36 \mathrm{pt}$ and $48 \mathrm{pt}$; one-level navigation instead of using menu structures; Arrange the buttons at the bottom of the interface so the input-hand will not hide the screen; Colour-neutral displays for visual impaired users; Redundant user guidance by colour-coding and blinking boxes; and Slow animation speed.

Authors such as Holzinger et al [38] define metrics for the design of applications for the older (not only mobjle applications), to do so they establish relationship among some criteria understandable and easy to identify for the older people (Likeability, Controllability, Simplicity, Privacy, Security Familiarity, etc.) with the traditional usability factors (Efficacy, Effectiveness, Satisfaction, Productivity, etc.).

Other authors carried out experiences with tablets that are successfully completed by older people [39]. From this experiences some issues related to the usability of the apps can be highlighted: The representation of web links can vary largely between different websites therefore they are not always perceived and recognized correctly; Simpler applications and features such as gesture control were quickly learnable and useable by the target group; Anglicizes are present when using the World Wide Web and not all the possible older people know them; And the way input fields work is not easy to understand for novice users (the necessity to tap in the input fields to show the virtual keyboard).

From these studies it is possible to see that different criteria is used to define the usability of a mobile app for an older person. Several of them can be grouped to de- 
fine a classification of factors to take into account. However, in order to deliver a popular application, the mobile application itself must be able to meet the specific needs of senior citizens in their daily life, so these needs should be also considered.

\subsection{Older people specific needs from mobile devices}

As the present project aims to define a repository of tools specifically designed for older people, the tools to include in the repository should be usable by older people but also should satisfy their needs. This means that older people needs should be explored. In this sense there are several studies.

VDI/VDE-IT, together with the AAL Association developed a model that classifies the needs of older people for their well being. They considered the following factors [40]: Health and Wellness, Home Care, Chores and Supply with Goods, Safety, Security and Privacy, Mobility, Information, Learning and Education, Social Interaction, Hobbies and Working life.

Other authors such as Plaza et al review this classification [41]. They distinguish between: Health, wellness and home care; Safety, security and privacy; Mobility, Information, learning and education; Chores and supply with goods; Religion/spirituality; Social Interaction; Hobbies and Working Life.

Abascal and Civit defined 6 requirements that mobile communication systems should provide older people: Personal Communication, Security, Social Integration, Access to Education and Labour Market and Autonomy. The apps should satisfy these requirements.

Finally, Gao and Koronios [36] explore different studies about the older people needs related to mobile devices and they needed: Health Monitoring tools, Personal Information tools, Social tools, Leisure and Sales tools, Safety and Privacy services.

It is possible see that most of these classifications take into account more or less the same areas and a combination of the is used as will be described in the Repository Approach section.

\subsection{Repositories of apps for older people}

Regarding with mobile apps repositories, there are not markets of apps specifically designed for older people. However it is possible find communities such as: AppsForOldPeople in Facebook [42], that recommend apps; other recommendation of apps by user communities [43-47]; and sections in the main mobile app repositories that can be related with some of older people needs (e.g.: Google Play and Apps Store have categories for health monitoring apps, home care; chores and supply with goods, etc.).

These initiatives are not defined thinking in older people and do not classify the tools for them. Given this contexts there is a necessity of the definition a repository of mobile apps, that satisfies older people needs, presents tools usable for them and gathers their feedback to classify the applications efficiently for the people of this collective. 


\section{Repository Approach of Mobile Apps for old people}

In the previous section was described that although there is lot of work about usability in mobile apps for older people, there are not specific repositories for them. The repository should consider the final end-user, the older persons. They have special requirements and characteristics that should be taken into account while designing the repository.

Taking this into account the present work poses a repository with functionalities to satisfy older people needs. These functionalities are:

- Apps Classification. The mobile apps should be classified attending to different criteria:

- Operative System. The repository should consider Android and iOS apps because they are the most common operative systems for mobile devices nowadays. However it should be flexible enough to add other operative systems (Windows Mobile, FirefoxOS, etc).

- Attending to older persons needs. In order to do so Plaza et al classification [41] is used because it takes into account a wider range of apps. In this classification will be added the adaptations of mobile phone operative systems for older persons (e.g.: VoiceOver, TalkBack, Big Launcher, Phonotto) [48].

- Usability features. The apps will be evaluated taken into account if they include some of the usability features desirable for these collectives (described in section 2.2.). A scale will be defined depending on the number of usability issues considered; the definition of such scale will depend on the evaluation of at least 30 tools for each operative system.

- Evaluation by older people. The final users of the repository will have the possibility to vote for their favorite tools and report feedback about them. This evaluation can be used to establish the top rated tools in the repository or in an existing category.

These criteria can be combined to show a specific showcase of the stored apps. For instance a user could be interested on a list of apps filtered by needs and evaluation.

- Apps Evaluation. The user of the repository can evaluate and provide feedback to an application. The evaluation will consist of a score between 0 and 10 . The feedback will be free text that later can be evaluated by using qualitative techniques in order to elaborate reports that facilitate recommendations and new classifications.

- Visualization and navigation for older people. All the content shown in the repository should take into account the special characteristics of the final users. Navigation should be simple and contents should provide different aids that for older to decide the tools to use.

- Web and Mobile adapted navigation. The repository should facilitate the navigation both through web browsers and through mobile browsers, so it is possible that some content should be adapted in this last case. 
- Advanced search and recommender. The repository should provide a functionality to search for tools based on the name of the tool or the possible classifications. It should recommend the apps for the final user can solve their specific needs. If the user is registered and have added which are his/her preferences and characteristics the recommender will use this information to suggest tools depending on the old person necessities.

- User and contents management. Functionalities to manage the users, the categories of apps, the recommendations, etc.;

- Download manager. Functionalities to facilitate apps downloading.

In order to carry out this development Drupal Content Management Platform [49] is chosen because its use can reduce the development time and facilitates the definition of a repository with the above described functionalities. Once it has been developed at least 100 apps will be included in the repository and pilots will be carried out with older people. Fig. 1. shows the proposed structured for the app repository.

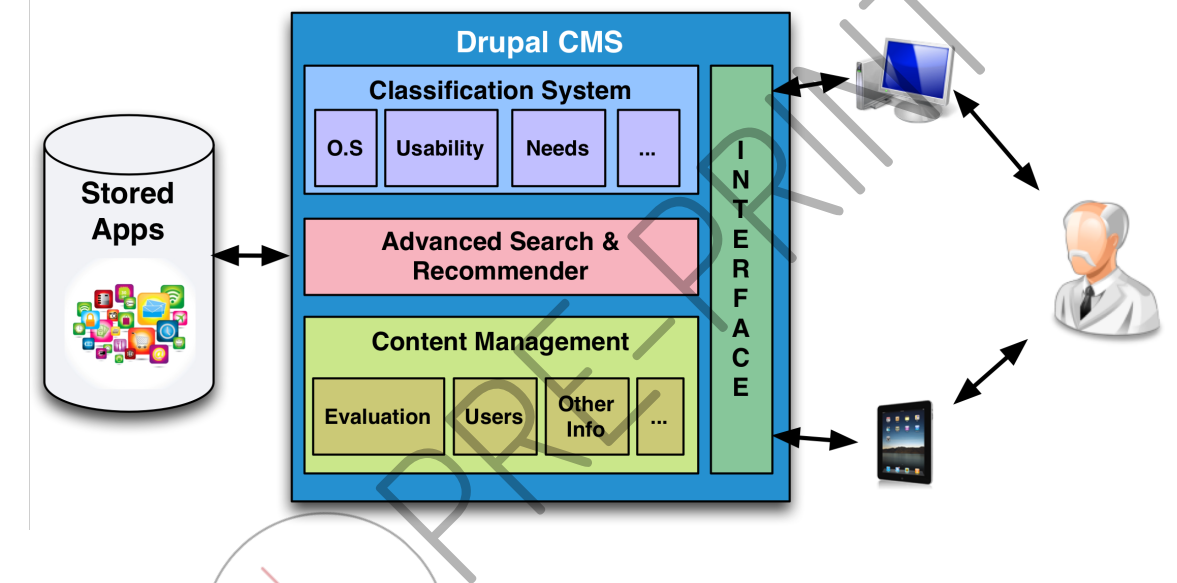

Fig. 1. App Repository description. It includes the store of apps and the Drupal implementation of the repository that can be accessed through a computer and a tablet.

\section{Conclusions}

The application of ICT to different contexts has associated an impact in the people involved on them. This specially evident in older people, ICT can be for them an inclusive or an exclusive factor. These people have special characteristics and not always the technology is adapted to them. However when it is ICT can open new possibilities for older people to socialize, learn, keep contact with family and friends, etc.

This paper is focused in mobile phones and how they are adapted to older people. It has carried out a review of different aspects related with the usability of the mobile, and the mobile apps for older people, which tools satisfy their needs and if it is possible to find repositories specially designed for them. From this study it was possible to see that there exist different factors to take into account when talking about mobile usability for older people, but not all authors agreed on them nor considered, in addi- 
tion such factors should be solved by the devices developers that do not always want to do changes in the devices for an specific collective. In addition apps usability features should be taken into account, in this case the different authors present also different conclusions about app usability but in this case is easier to address them when developing tools. However this do not guarantee that an app can be used by older persons, it is important to take into account also if the apps are solving the needs and interests of old people. In this sense several authors present more or less the same areas of interest of older people about mobile applications.

Taking this into account a repository of apps for older people is going to be developed with special attention to usability features and with the idea to satisfy their special requirements.

\section{Acknowledges}

This work is partially supported by the Cátedra Telefónica of the University of León (CTULE13-3) and by the Regional Council of Education of the Junta de Castilla y León through the project MPLE (ref. SA294A12-2).

\section{References}

1. ITU: The Little Data Book on Information and Communication Technology 2013. The World Bank - International Telecommunication Union (2013)

2. Graham, J.: 'Elderly' No More. The New Old Age - Caring and Coping. The New York Times (2012)

3. World-Health-Organization, Definition of an older or elderly person. Proposed Working Definition of an Older Person in Africa for the MDS Project, http://www.who.int/healthinfo/survey/ageingdefnolder/en/. Accessed 20/02/2014

4. Prensky, M.: Digital natives, digital immigrants. On the Horizon 9, (2001)

5. Prensky, M.: Digital Natives, Digital Immigrants, Part II: Do They Really Think Differently? On the Horizon 9, (2001)

6. Burdick, D.: Digital divide or tool for understanding and collaboration: computers and intergenerational relationships. 54th Anual Scientific Meeting of the Gerontological Society of Americas, Chicago, USA (2001)

7. White, H., McConnell, E., Clipp, E., Bynum, L., Teague, C., Navas, L., Craven, S., Halbrecht, H.: Surfing the net in later life: A review of the literature and pilot study of computer use and quality of life. Journal of Applied Gerontology 18, 358-378 (1999)

8. Weatherall, J.W.A.: A grounded theory analysis of older adults and information technology. Educational Gerontology 26, 371-386 (2000)

9. Madden, G., Savage, S.: Some economic and social aspects of residential Internet use in Australia. Journal of Media Economics 13, 171-185 (2000)

10. Hernández-Encuentra, E., Pousada, M., Gómez-Zúñiga, B.: ICT and Older People: Beyond Usability. Educational Gerontology 35, 226-245 (2009)

11. Teo, T.: Demographic and motivation variables associated with Internet usage activities. Internet Research-Electronic Networking Applications and Policy 11, 125-137 (2001)

12. Fundación-Vodafone-España: TIC y Mayores (2012)

13. ITU: Mesuring the Information Society. International Telecommunication Union (2012) 
14. Kurniawan, S.: Older people and mobile phones: A multi-method investigation. International Journal of Human-Computer Studies 66, 889-901 (2008)

15. García-Peñalvo, F.J., Conde, M.Á., Pozo, A.: A Mobile Personal Learning Environment Approach. In: Shumaker, R. (ed.) Virtual, Augmented and Mixed Reality. Systems and Applications. 5th International Conference, VAMR 2013 Held as Part of HCI International 2013, vol. LNCS 8022, pp. 132-141. Springer Verlag, Las Vegas, NV, USA (2013)

16. García-Peñalvo, F.J., Conde, M.Á.: The impact of a mobile Personal Learning Environment in different edu-cational contexts. Universal Access in the Information Society (In press)

17. Casany, M.J., Alier, M., Mayol, E., Piguillem, J., Galanis, N., García-Peñalvo, F.J., Conde, M.A.: Moodbile: A framework to integrate m-learning applications with the LMS. Journal of Research and Practice in Information Technology 44, 41-61 (2012)

18. Ziefle, M., Bay, S.: How older adults meet complexity: Aging effects on the usability of different mobile phones. Behaviour \& Information Technology 24, 375-389 (2005)

19. Abran, A., Khelifi, A., Suryn, W., Seffah, A.: Usability Meanings and Interpretations in ISO Standards. Software Quality Journal 325-338 (2003)

20. Chamorro-Valor, S.J.: Análisis de usabilidad de dispositivos móviles con diferentes interfaces de usuario. Ingeniería de la Organización, Administración de Empresas y Estadística, vol. Ingeniería en Telecomunicaciones. Universidad Politécnica de Madrid, Madrid (2011)

21. Kjeldskov, J., Stage, J.: New techniques for usability evaluation of mobile systems. International Journal of Human-Computer Studies 60, 599-620 (2003)

22. Coursaris, K., Kim, D.: A Qualitative Review of Empirical Mobile Usability Studies. Proceedings of the Twelfth Americas Conference on Information Systems, Acapulco, Mexico (2006)

23. Hussain, A., Ferneley, E.: Usability metric for mobile application: a goal question metric (GQM) approach. In: 10th International Conference on Information Integration and Webbased Applications \& Services, pp. 567-570 (2008)

24. Nielsen, J., Budiu, R.: Mobile Usability. Pearson Education (2012)

25. Oehl, M., Sutter, C., Ziefle, M.: Considerations on Efficient Touch Interfaces - How Display Size Influences the Performance in an Applied Pointing Task. In: Smith, M., Salvendy, G. (eds.) Human Interface and the Management of Information. Methods, Techniques and Tools in Information Design, vol. 4557, pp. 136-143. Springer Verlag, Berlin Heidelberg, (2007)

26. Urdaibay-Villaseca, P.T.: Usability of Mobile Devices for Elderly People. Department of Information Technology, vol. Master of Science in Software and Inforamtion Systems. National University of Ireland, Galway, Ireland (2010)

27. Lin, C.J., Hsieh, T.-L., Shiang, W.-J.: Exploring the Interface Design of Mobile Phone for the Elderly. In: Kurosu, M. (ed.) Human Centered Design, vol. 5619, pp. 476-481. Springer Verlag, Berlin Heidelberg (2009)

28. Arning, K., Ziefle, M.: Barriers of Information Access in Small Screen Device Applications: The Relevance of User Characteristics for a Transgenerational Design. In: Stephanidis, C., Pieper, M. (eds.) Universal Access in Ambient Intelligence Environments, vol. 4397, pp. 117-136. Springer Verlag, Berlin Heidelberg (2007)

29. Fujioka, R., Akiba, T., Okada, H.: Evaluation of Pointing Efficiency on Small Screen Touch User Interfaces. In: Salvendy, G., Smith, M. (eds.) Human Interface and the Management of Information. Information and Interaction, vol. 5618, pp. 375-384. Springer Verlag, Berlin Heidelberg (2009) 
30. Jin, Z.X., Plocher, T., Kiff, L.: Touch Screen User Interfaces for Older Adults: Button Size and Spacing. In: Stephanidis, C. (ed.) Universal Acess in Human Computer Interaction. Coping with Diversity, vol. 4554, pp. 933-941. Springer Verlag, Berlin Heidelberg (2007)

31. Lee, C.-F., Kuo, C.-C.: Difficulties on Small-Touch-Screens for Various Ages. In: Stephanidis, C. (ed.) Universal Acess in Human Computer Interaction. Coping with Diversity, vol. 4554, pp. 968-974. Springer Verlag, Berlin Heidelberg (2007)

32. Kobayashi, M., Hiyama, A., Miura, T., Asakawa, C., Hirose, M., Ifukube, T.: Elderly User Evaluation of Mobile Touchscreen Interactions. In: Campos, P., Graham, N., Jorge, J., Nunes, N., Palanque, P., Winckler, M. (eds.) Human-Computer Interaction - INTERACT 2011, vol. 6946, pp. 83-99. Springer Verlag, Berlin Heidelberg (2011)

33. HIMSS: Selecting a Mobile App: Evaluating the Usability of Medical Applications. Healthcare Information and Management Systems Society (2012)

34. Ryan, C., Gonsalves, A.: The effect of context and application type on mobile usability: an empirical study. 28th Australasian conference on Computer Science, vol. 38, pp. 115-124 (2005)

35. Zhang, D., Adipat, B.: Challenges, Methodologies, and issues in the Usability Testing of Mobile Applications. International Journal of Human-Computer Interaction 18, 293-308 (2005)

36. Gao, J., Koronios, A.: Mobile application development for senior citizens. 14th Pacific Asia Conference on Information Systems, pp. 214-223. National Taiwan University, Taipei, Taiwan 9-12 July 2010 (2010)

37. Lorenz, A., Oppermann, R.: Mobile health monitoring for the elderly: Designing for diversity. Pervasive and Mobile Computing 5, 478-495 (2009)

38. Holzinger, A., Searle, G., Kleinberger, T., Seffah, A., Javahery, H.: Investigating Usability Metrics for the Design and Development of Applications for the Elderly. In: Miesenberger, K., Klaus, J., Zagler, W., Karshmer, A. (eds.) Computers Helping People with Special Needs, vol. 5105, pp. 98-105. Springer Verlag, Berlin Heidelberg (2008)

39. Werner, F., Werner, K., Oberzaucher, J.: Tablets for Seniors - An Evaluation of a Current Model (iPad). In: Wichert, R., Eberhardt, B. (eds.) Ambient Assisted Living, pp. 177-184. Springer Verlag, Berlin Heidelberg (2012)

40. Gaßner, K., Conrad, M.: ICT enabled independent living for elderly. A status-quo analysis on products and the research landscape in the field of Ambient Assisted Living (AAL) in EU-27. Institute for Innovation and Technology (iit) Berlin, Germany (2010)

41. Plaza, I., Martín, D., Martin, S., Medrano, C.: Mobile applications in an aging society: Status and trends. Journal of Systems and Software 84, 1977-1988 (2011)

42. AppsForOldPeople, Apps For Old People, https://http://www.facebook.com/AppsForOldPeople/info, Accessed 20/02/2014

43. PandaApp, Top 10 Best Apps for Older People, Panda App iPhone Channel, http://iphone.pandaapp.com/news/05082013/024405898.shtml, Accessed 20/02/2014

44. Anderson, J., Best iPad Apps for Senior Citizens, AssitedLiving.com, http://www.assistedliving.com/best-ipad-apps-for-seniors/, Accessed 20/02/2014

45. Myageingparent, Top iPad apps for the elderly, http://www.myageingparent.com/top-ipadapps-for-the-elderly/, Accessed 20/02/2014

46. Myageingparent, More top apps for older people, http://www.myageingparent.com/topipad-apps-for-the-elderly/, Accessed 20/02/2014

47. Actitud50, Aplicaciones móviles para mayores de 50 años, http://www.actitud50.com/es/tecnologia/descargar-aplicaciones-en-moviles-y-tabletaspara-mayores-de-50-anos-20122603.html, Accessed 20/02/2014 
48. Pastor, J., Móvil y tercera edad (II): terminales y apps para el público senior, http://mobileworldcapital.com/es/articulo/137, Accessed 20/02/2014

49. Drupal, Drupal, https://drupal.org/, Accessed 20/02/2014

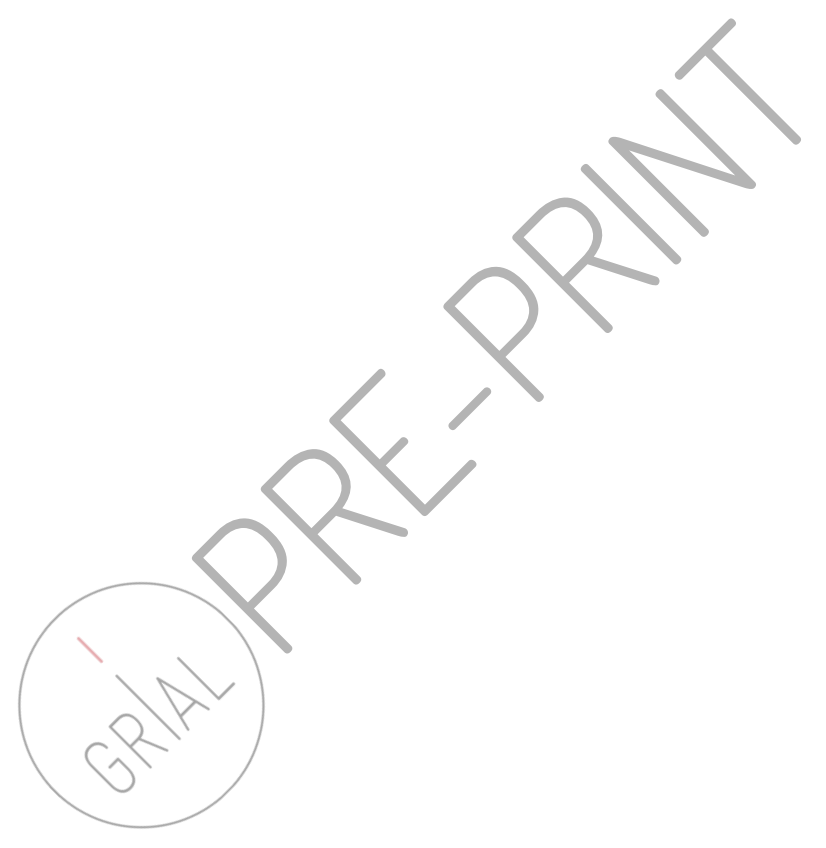

